\title{
RESEARCH CONCERNING FABRICATION OF FIBROUS OSTEOCONDUCTIVE PLGA/HAP NANOCOMPOSITE MATERIAL USING THE METHOD OF ELECTROSPINNING FROM POLYMER SOLUTION
}

\author{
Izabella Krucińska, Maciej Boguń, Olga Chrzanowska, Michał Chrzanowski, Paulina Król
}

Technical University of Lodz, Department of Material and Commodity Sciences and Textile Metrology, ul. Żeromskiego 116, 90-924 Łódź, Poland E-mail: maciek.bogun@wp.pl

\begin{abstract}
:
The aim of the work was to obtain nano fibrous structures from biodegradable polymer with the addition of hydroxyapatite using electrospinning technique. Research was conducted with two types of solvent: dichloromethane and 50:50 mixture of dimethyl sulfoxide and dichloromethane. As a polymer a copolymer of L-lactide and glycolide (PLGA), commercial product with trade name Resomer ${ }^{\circ} L G$ 824, was used. The preliminary electrospinning tests enabled to match optimal polymer solution concentration of tested samples. Rheological properties of all tested polymer solutions has been determined. Influence of electrospinning conditions and the type of solvent on macroscopic structure has been investigated.
\end{abstract}

\section{Keywords:}

Electrospinning, nanofibres, biodegradable polymer, PLGA

\section{Introduction}

High level of interest in biodegradable polymers results from the environmental policy of many states, which aim to make the materials themselves, as well as the technological processes, more environment-friendly and to facilitate recycling of the products after use. Polylactic acid (PLA) and its copolymers constitute the largest group of polymers, classified as aliphatic polyesters, which are characterized by biodegradability under appropriate environmental conditions. The most popular biodegradable, biocompatible polymers of this group include: poly(glycol acid) (PGA), PLA, poly( $\varepsilon$-caprolactone) (PCL), polyhydroxybutyrate, polyhydroxyalkanoate, or their copolymers [1-5]. Exposure to microorganisms and humidity leads to cleavage of the ester bonds and degradation of the polymer chain to form smaller units - oligomers. The obtained degradation products are processed by anaerobic bacteria to yield carbon dioxide and water [6-8]. In this manner, the raw material for PLA synthesis is obtained by fermentation of a biodegradable material - sugar cane, maize, or other carbohydrates. A product obtained from such a polymer becomes, after the decomposition process, another phase of the closed cycle of PLA processing and recycling. The wide spectrum of interest in this polymer results also from the fact that PLA undergoes degradation in living organisms as well. The product of PLA decomposition is a compound occurring in nature; therefore, it can be eliminated via typical metabolic pathways (Krebs or Corich cycle) and is not hazardous for the organism $[5,6]$. Owing to its structure and the potential to occur in two different, optically active, chiral forms: (L)-lactide (D)-lactide; the produced polymer can possess properties appropriately adjusted to the needs and to the method of further processing. Additionally, it is possible to program precisely the chemical structure, the molecular mass, as well as the sequence of the particular units or comonomers in the polymer chain, affecting many other properties at the same time, by selection of the method of synthesis and the used catalysts. Obtaining lactic acid involves polycondensation of lactide oligomers, which results in prepolymer formation. Using an appropriate catalyst, prepolymer synthesis is then conducted and the obtained product is removed from the reaction medium [2]. There are essentially two groups of methods to obtain PLA. The first one involves direct condensation polymerization of lactic acid under high vacuum and at high temperature. However, the above method allows obtaining polymer of relatively low molecular weight, whereas the occurrence of transesterification process results in the formation of ring compounds of various sizes. The difficult aspects of the method include the necessity to use a large reactor, the drainage of water from the mixture characterized by high viscosity, the retrieval of the solvent and increased racemization. That is why, the method is not applied in industrial scale production of the polymer [2,5,9-13]. Ring opening polymerization is a triphasic synthesis process for controlling the molecular weight of the obtained polymer; therefore, this method is preferred for fabrication of the polymer on a mass scale. Owing to adjustments of the reaction time, process temperature, and the type of catalyst used, it is possible to control the proportions and sequences of $D$ - and L-lactide in the final polymer chain. Tin and aluminum compounds are the group of commonly used catalysts [2,4,5,13-15]. Despite their high activity and effectiveness, they are regarded as toxic [2]. To improve the biocompatibility of the polymer in the synthesis process, non-toxic catalysts have been proposed. The research of many authors [16-23] concerning biocompatibility increase of polymers designed for medical applications has been based on the use of calcium iron, magnesium, and zinc compounds as catalysts. Unfortunately, despite lower toxicity, these compounds 
demonstrate the capability of PLA racemization, especially at high temperatures. Moreover, they may contribute to hydrolysis, oxidation, or degradation initiated in another way [2].

Textile engineering is a developing and promising area of research, focused on obtaining materials with specific properties as a result of processes allowing to adjust the parameters determining directly the structure and the properties of the obtained products. A wide spectrum of methods allowing to process high-molecule compounds into various fibrous products and composite materials as well as the potential for easy modification of polymers make it possible to eliminate the problems resulting from high susceptibility and sensitivity of PLA to thermal and hydrolytic degradation. In the case of PLA processing, susceptibility to hydrolysis can be initiated by using high temperature, or by the presence of even small amounts of humidity, not exceeding 100 ppm, in the polymer [7,24,25].

In medical applications, fibrous structures are advantageous because of anisotropy of properties and because of their morphology; the characteristics of these products resemble most closely those of the living tissues. Modifications of their structure, surface, and composition by adding biologically active substances and modifiers allow to produce biomimetic structures. Depending on the selected method of fiber formation, various effects related to the structure and properties of the fabricated fibers and fibrous structures can be obtained. The most common methods used to form fibers and fibrous substrates from polymer melt make it possible to obtain fibers with high-strength parameters within the 410-870 $\mathrm{MPa}$ range. However, there are reports in the relevant literature concerning a significant decrease in the molecular mass of the processed polymer, reaching even $70-80 \%$. As a result of polymer shredding, heating, and stretching in a hot medium, uncontrolled degradation of the material occurs due to exposure to high temperature $[5,26,27]$. In addition, the presence of trace amounts of water exerts an unfavorable effect. Obtaining PLA fibers from the solution not only contributes to reduction of that phenomenon but also enables easy introduction of various modifiers, those sensitive to temperature, as well as viable cells or proteins. Owing to the development of the dry spinning method for fiber formation from the solution [33], it is possible to obtain fibers characterized by strength parameters comparable to those of the fibers obtained from polymer melt, eliminating at the same time the unfavorable degradation process of the polymer material.

Electrospinning is one of the most popular methods used in fabrication of fibers and fibrous substrates. It is one of the numerous methods, including e.g. phase separation, extension, or self-organization, used to obtain nanofibrous scaffolds. The first patent concerning electrospinning of fibers was published in 1934 by Formhals [34-36]. Despite many years of research and numerous studies on this method, it is not used on a mass scale, except for Donaldson Company, Inc. (Minneapolis), which manufactures air-filtering materials. However, interesting results of research, high spectrum of potential applications of the obtained fibrous materials, unique properties unknown to date, as well as the possibility of infinite modifications determine ideal conditions for further development of this technology. During the recent years, numerous research centers have focused their interest on obtaining nanofibers from biodegradable, biocompatible synthetic polymers, as well as from the natural ones, originating from the living organisms, such as: PGA, PLA, PGLA, PCL, PDO, collagen (types I-IV), gelatin, elastin, silk, fibrinogen, or hemoglobin [36]. The polymers that still cause considerable problems while formed by electrospinning are alginates and hyaluronic acid. The occurrence of repelling forces due to polyelectrolytic nature of these polymers makes the electrospinning process more difficult, or even impossible. It is possible to obtain fibers from these biopolymers by using special additives, but the problems cannot be eliminated completely [37]. The electrospinning method allows to obtain fibers with diameters ranging from a few nanometers to over 1 $\mu \mathrm{m}$. Most polymers processed with this method are dissolved in an appropriate solvent, as a result of which polymer solution is obtained. Fibers can also be produced by electrospinning from polymer melt, but it is much more difficult considering that spinning should take place under vacuum conditions [38]. By selection and control of technological parameters of the process, material-related variables, and also the type of collector used, or modification of the process itself, structures differentiated with respect to orientation and arrangement of the fibers, morphology and properties can be obtained, allowing to produce systems with appropriate fiber orientation and disposition, nano- or submicron composite fibers, highly porous nanofibers, or live cell scaffolds [36,38-46].

In most cases, fibrous nanostructures obtained by electrospinning are fabricated to develop controlled bioactive substance or drug release systems, scaffolds for cell cultures, membrane materials for ultrafiltration, modern dedicated dressing materials, advanced medical implants, or filter materials. The wide spectrum of application of nanofibers results from their size, which is associated with well-developed internal surface (ensuring excellent absorption or effective release) and the system of open pores. Such characteristics make it possible to introduce the active substance into the porous structure of the fibrous material, or directly into the polymer matrix, warranting its slow release. As far as filtering materials and membranes are concerned, they are capable of retaining particles of specific size and their effective separation. Such a material as PLA seems ideal for these purposes, considering its biodegradability and non-invasiveness, both for biological systems and for living organisms.

In the study by lonescu et al. [47], the research was focused on composites based on microspheres and nanofibers made, among others, of biodegradable polymers, including PCL, poly(ethylene oxide), PGLA, and poly(vinyl alcohol) (PVA), containing additionally the following biomolecules: bovine serum albumin and chondroitin sulfate. The microspheres introduced to the polymer solution were then formed to obtain fibrous substrates. Depending on the material of the microcapsules and on the nanofibrous system into which they were introduced, it was possible to wash out a particular system and to obtain fibrous structures with the capsules dispersed in the porous structure. As concluded in that study, the introduction of microcapsules into the analyzed system did not affect significantly either the mechanical properties of the 
obtained scaffolds or the process of release of microspheres trapped inside the composite. The results concerning active factors release kinetics within 30 days are promising, as slow and homogeneous release of biomolecules was noted.

The studies concerning electrospinning of PLA and its copolymers with different bioactive factors such as antibiotics, anticancer drugs [48], lyophilic and hydrophilic substances, numerous proteins, genes, DNA [49-51], or silver nanomolecules have been reported in the literature. Fibrous composites with nanoadditives such as montmorillonite (MMT) and titanium dioxide have also been obtained [48].

Position [52], concerned with two-component fibers obtained by electrospinning from PLC and PLA, focused primarily on developing a system of controlled antibiotic release. By modification of proportions between the individual polymer, the concentration of the spinning solutions and parameters of the process, it was possible to select the variant providing the optimal conditions to obtain the desired drug release rate.

In contrast, the study by Bhattarai et al. [53] presents the effect of PLA- and poly(ethylene glycol) -based fibrous structures obtained by electrospinning with methylene chloride and DMF used on the cellular response of NIH 3T3-type murine fibroblasts. Despite hydrophobic characteristics, it was possible to obtain structures with the appropriate proportions of polymers enhancing the biological activity of the investigated cells. Both cell proliferation and morphology and the interaction between the investigated material and the cells were observed to be favorable. The promising results of the study allow to expect that there is a potential for fabrication of fibrous structures making it possible to obtain specific cellular responses.

The aim of this paper is to present the possibilities of obtaining nanofibrous structures produced by electrospinning from a polymer solution, constituting a copolymer of L-lactide and glycolide, combined in proportions ranging from 79:21 to $85: 15$ with the addition of hydroxyapatite. The material has been designed to be used for regeneration of osseous tissue as an osteoconductive (because of the porous structure of the fibrous substrate) and osteoinductive material (the presence of a bioactive substance - nanohydroxyapatite - HAp).

\section{Characterization and selection of the study material}

The study was carried out using a polymer referred to as Resomer®LG 824, a copolymer of L-lactide and glycolide combined in proportions ranging from 79:21 to $85: 15$, manufactured by Boehringer Ingelheim (Germany). To obtain fibers, two types of solvents were used: dichloromethane and 50:50 mixture of dimethyl sulfoxide and dichloromethane. To confer osteoinductive properties to the fibers, hydroxyapatite powder with grain size below $200 \mathrm{~nm}$, manufactured by Sigma-Aldrich (Germany), was introduced into the solution. The characteristics of the polymer were obtained using gel chromatography method (SEC/GPC); the results of that analysis are presented in Table 1.

Investigations using DSC demonstrated that the used polymer is a crystalline polymer with vitrification temperature of $57.71^{\circ} \mathrm{C}$ and crystalline areas melting temperature of $156.52^{\circ} \mathrm{C}$. The melting enthalpy was $35.23 \mathrm{~J} / \mathrm{g}$.

To obtain the polymer solution, the preliminary experiments were carried out using dichloromethane. Three types of solutions with $10 \%, 6 \%$ and $4 \%$ wt polymer concentrations were obtained with the addition of $1 \%$ wt (as related to the polymer) hydroxyapatite. For that purpose, hydroxyapatite was mixed with dichloromethane using a sonic stirrer, then polymer was added to the suspension of hydroxyapatite in dichloromethane and the solution was prepared using a magnetic stirrer. The preliminary electrospinning trials demonstrated that only the $6 \%$ solution was suitable for further experiments. The $10 \%$ solution was characterized by too high viscosity to allow obtaining fibers by electrospinning, whereas the $4 \%$ one yielded a film instead of a fibrous substrate. Therefore, the $6 \%$ solution, whose rheological properties were determined with a rotation rheometer (manufactured by Anton Paar), was used in further research. The results are presented in Table 2.

The second type of solution was obtained using a mixture of solvents - dimethyl sulfoxide and dichloromethane combined in a 50:50 proportion. Analogical to the case discussed above, $15 \%, 10 \%, 6 \%$, and $4 \%$ with $1 \%$ wt hydroxyapatite (as related to the polymer amount) were added, as well as solutions

Table 1. Characteristics of the study material

\begin{tabular}{|c|c|c|c|c|}
\hline Polymer & $\begin{array}{c}\text { Specific viscosity } \\
(\mathbf{d} / \mathbf{g})\end{array}$ & $\begin{array}{c}\text { Number average } \\
\text { molecular mass }\left(M_{\mathrm{n}}\right)\end{array}$ & $\begin{array}{c}\text { Weight average } \\
\text { molecular mass }\left(M_{\mathrm{w}}\right)\end{array}$ & $\begin{array}{c}\text { Degree of } \\
\text { polydispersity }\left(M_{\mathrm{w} /} M_{\mathrm{n}}\right)\end{array}$ \\
\hline PLGA & 1.94 & 128,116 & 334,283 & 2.6 \\
\hline
\end{tabular}

Table 2. Rheological characteristics of PGLA/dichloromethane solution used for electrospinning in preliminary studies.

\begin{tabular}{|c|c|c|c|}
\hline Polymer & $\begin{array}{c}\text { Concentration of spinning } \\
\text { solution (\% wt) }\end{array}$ & Rheological parameter $(n)$ & Rheological parameter $(k)$ \\
\hline PLGA/ 1\% HAp & 6 & 0.994 & 9.86 \\
\hline
\end{tabular}


without HAp addition. The preliminary electrospinning trials confirmed the applicability of two solution types with $6 \%$ and $4 \%$ polymer concentration. The $15 \%$ and $10 \%$ solutions were characterized by too high viscosity to undergo electrospinning. The rheological properties of the solutions used in further research are presented in Table 3.

\section{Fibrous substrate formation method}

The fibrous substrate was formed by electrospinning using a multicapillary experimental stand described in another study [54]. The experiments were conducted using capillaries $0.9 \mathrm{~mm}$ in diameter with drum collector rotation speed of $35 \mathrm{rpm}$ in the first series and $20 \mathrm{rpm}$ in the second one, with variable distances between the capillaries and the collectors and variable voltages applied to the upper electrode.

\section{Results}

In the first series of measurements, a 6\% wt PLGA solution in dichloromethane with the addition of $1 \%$ hydroxyapatite as related to the polymer mass was used. Electrospinning was conducted with the distances between the capillaries and the collector drum set at 15,25 , and $35 \mathrm{~cm}$, respectively. Increasing the collection distance correlated with an increase in voltage applied to the upper electrode. The experiments were conducted at $15-16^{\circ} \mathrm{C}$ because of high volatility of the solvent. Higher temperature caused polymer curing when it was still on the needle. The obtained fleeces were analyzed to assess the transverse dimensions of the fibers that formed them. Transverse dimensions were assessed using Lucia G software, designed for the analysis of images obtained using an electron microscope (SEM) manufactured by FEI Nova Nano SEM. To calculate the transverse dimension values, approximately 200 fibers were analyzed for each variant. The results of the studies together with examples of fleece images are presented in Table 4.

The presented results indicate a significant dispersion of the fiber transverse dimension values. Despite various spinning conditions, it was impossible to obtain fibers with average geometric dimensions within a few hundred nanometers range. The obtained products should be classified as microfibers, because their transverse dimensions exceeded $1 \mu \mathrm{m}$ in each case. The presented image indicates the formation of fibers characterized by a very wide spectrum of transverse dimensions ranging from $<1 \mu \mathrm{m}$ to $11 \mu \mathrm{m}$, making up the non-woven material. Therefore, further attempts to produce fibrous substrates from another type of solutions, characterized in Table 2, were undertaken. Variable distances between capillaries and the drum were also used in this case, increasing the voltage values as the fiber collection distance was increased.

The results of the experiments for solutions both with and without hydroxyapatite addition are presented in Tables 5 and 6 . In the first cycle of the experiments, the set parameters of the electrospinning process were intended to determine the optimal distance between the electrodes. Three distances 15,25 , and $30 \mathrm{~cm}$ - were tested at a constant voltage value of $30 \mathrm{kV}$. The experiments were conducted with the drum collector rotation speed of $20 \mathrm{rpm}$. The results obtained for that cycle of experiments are presented in Table 5.

As it follows from the completed experiments, the smallest transverse dimension of the fibers was obtained for the $25-\mathrm{cm}$ distance between the electrodes. The fiber transverse dimension for such setting of the experimental stand was $670 \mathrm{~nm}$, with the standard deviation of $170 \mathrm{~nm}$. Further experiments were conducted so as to keep the constant distance of $25 \mathrm{~cm}$ and change the voltage applied to the upper electrode to 20 and $15 \mathrm{kV}$. With such technological parameters, the fibers of 800 and $750 \mathrm{~nm}$ transverse dimensions, respectively, were obtained. The presented stage of the experiments was completed at that point, specifying the following conditions as optimal for fiber formation to obtain the desirable dimensions: distance between the electrodes $25 \mathrm{~cm}$, difference of potentials between the electrodes $30 \mathrm{kV}$, needle diameter $0.9 \mathrm{~mm}$, rotation speed of the drum collector $20 \mathrm{rpm}$, and needle bar speed $20 \mathrm{~mm} / \mathrm{s}$.

The subsequent stage of the study concerned the conditions of fiber formation from PLGA solution in DMSO/DCM solvent mixture with $1 \%$ addition of hydroxyapatite. The experimental procedure was analogical to the previous case. In the first series of experiments, constant voltage value of $30 \mathrm{kV}$ was adopted, with variable distances between the electrodes. The results of the experiments are described in Table 6. The presented results indicate that the quality of the obtained fibers is considerably worse than that of the fibers formed without hydroxyapatite added, despite the fact that the average transverse dimension did not differ significantly from that of the fibers spun from pure PLGA polymer. Segmental thickenings of various lengths are observed in the fibers. The

Table 3. Rheological characteristics of PLGA/DMSO/DCM solutions used for electrospinning at the final stage of the study.

\begin{tabular}{|c|c|c|c|}
\hline Polymer & $\begin{array}{c}\text { Concentration of spinning solution } \\
(\% \text { wt) }\end{array}$ & $\begin{array}{c}\text { Rheological parameter } \\
(n)\end{array}$ & $\begin{array}{c}\text { Rheological parameter } \\
(k)\end{array}$ \\
\hline PLGA/1\% HAp & 4 & 0.717 & 1.40 \\
\hline PLGA & 4 & 0.668 & 1.04 \\
\hline PLGA/1\% HAp & 6 & 0.422 & 7.99 \\
\hline PLGA & 6 & 0.653 & 1.31 \\
\hline
\end{tabular}


Table 4. Results of diameter measurements and images of fibers electrospun from $6 \%$ PLGA solution in dichloromethane with $1 \%$ nanoadditive hydroxyapatite - as related to the polymer mass.

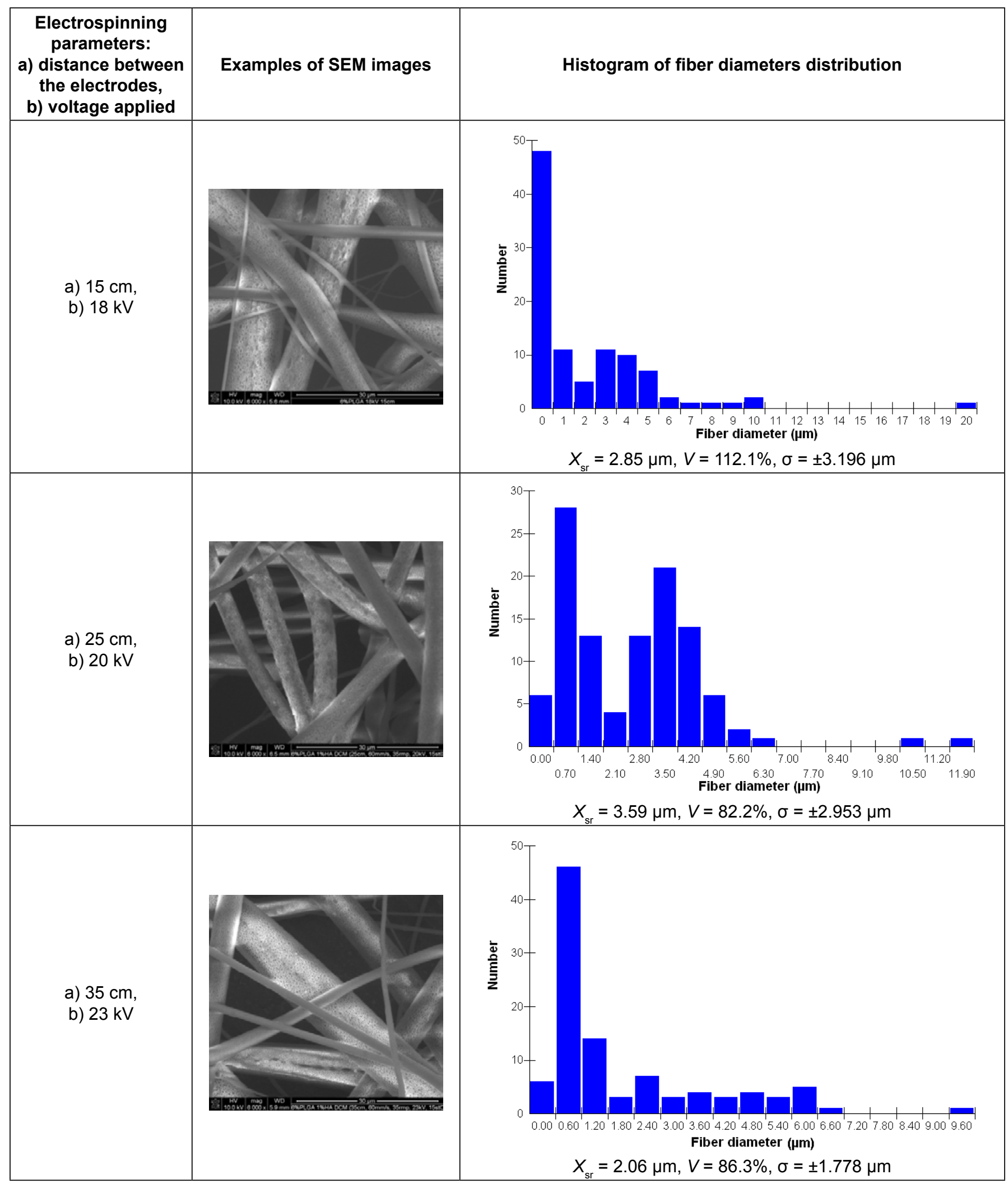

above phenomenon may result from a significant increase in consistency coefficient $k$ of the polymer solution with $1 \%$ HAp content in comparison with that of the pure solution. The observed increase reaches over $600 \%$. The analysis of results indicates that the least significant dispersion of transverse dimensions was obtained for the variant, which was optimal in the previous experiment, i.e. for $25 \mathrm{~cm}$ distance between the electrodes and $30 \mathrm{kV}$ voltage. Voltage reduction to 20 and $15 \mathrm{kV}$ did not increase the homogeneity of fibers, but only a decrease in their average transverse dimensions from the value of $0.9 \mu \mathrm{m}$ with $0.37 \mu \mathrm{m}$ standard deviation to $0.69 \mu \mathrm{m}$ with $0.34 \mu \mathrm{m}$ standard deviation. In such 
Table 5. Results of diameter measurements and images of fibers obtained by electrospinning from 6\% PLGA solution in a mixture of solvents: dimethyl sulfoxide and dichloromethane in 50:50 proportion.

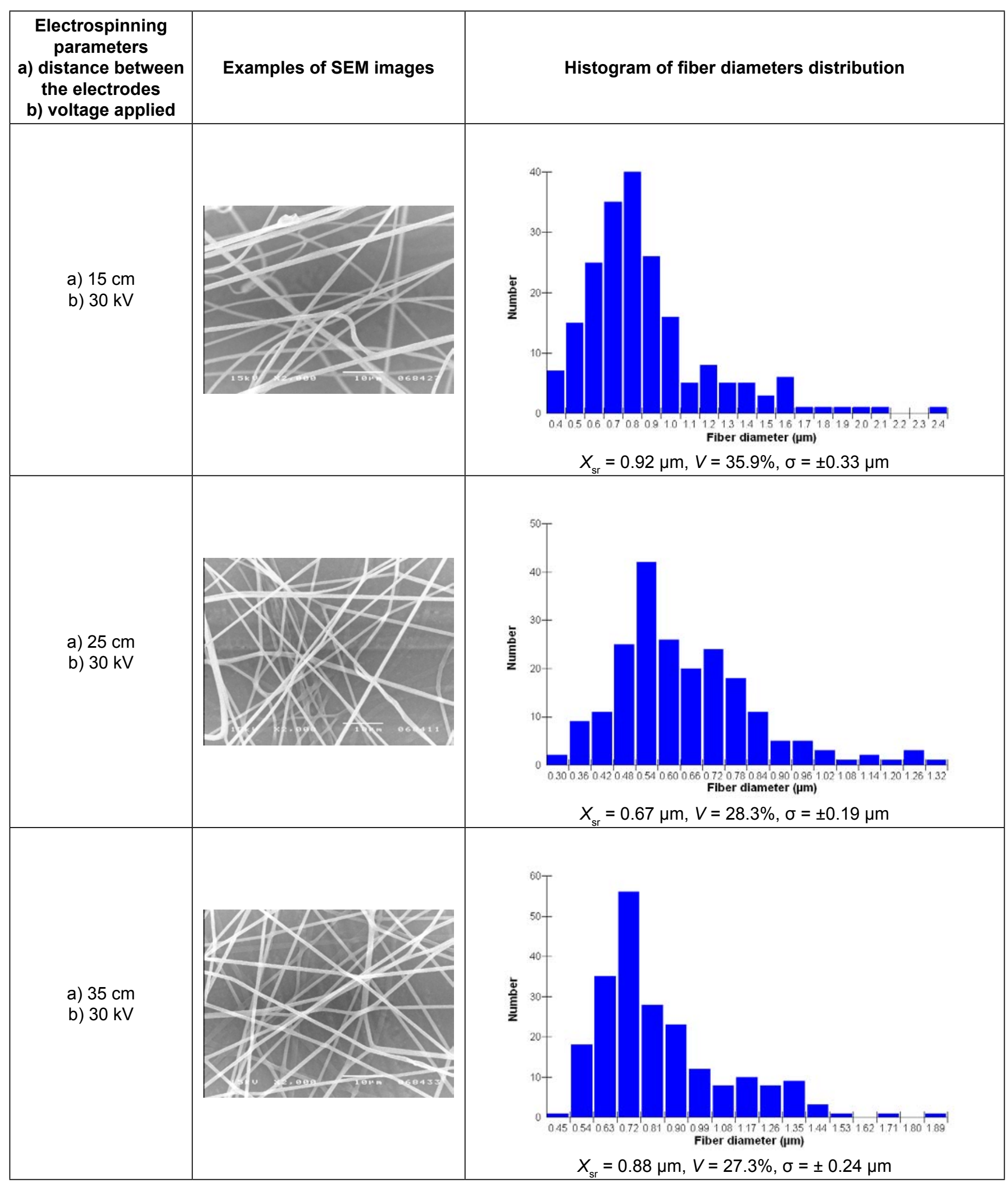

a situation, it was decided to conduct the electrospinning process for 4\% PLGA solution in DMSO/DCM, also with the content of hydroxyapatite amounting to $1 \%$ as related to the polymer mass. The consistency coefficient for that solution is similar to the value obtained for $6 \%$ PLGA solution, for which the course of the electrospinning process was stable, yielding fibers of a few hundred nanometers dimensions. The fibers were electrospun under the optimal conditions selected for the 6\% PLGA in DMSO/DCM solution variant, i.e. with $30 \mathrm{kV}$ voltage applied and $25 \mathrm{~cm}$ distance between the electrodes. The results of the experiments are presented in Table 7. 
Table 6. Results of diameter measurements and images of fibers obtained by electrospinning from 6\% PLGA solution with $1 \%$ HAp added in a mixture of solvents: dimethyl sulfoxide and dichloromethane in 50:50 proportion.

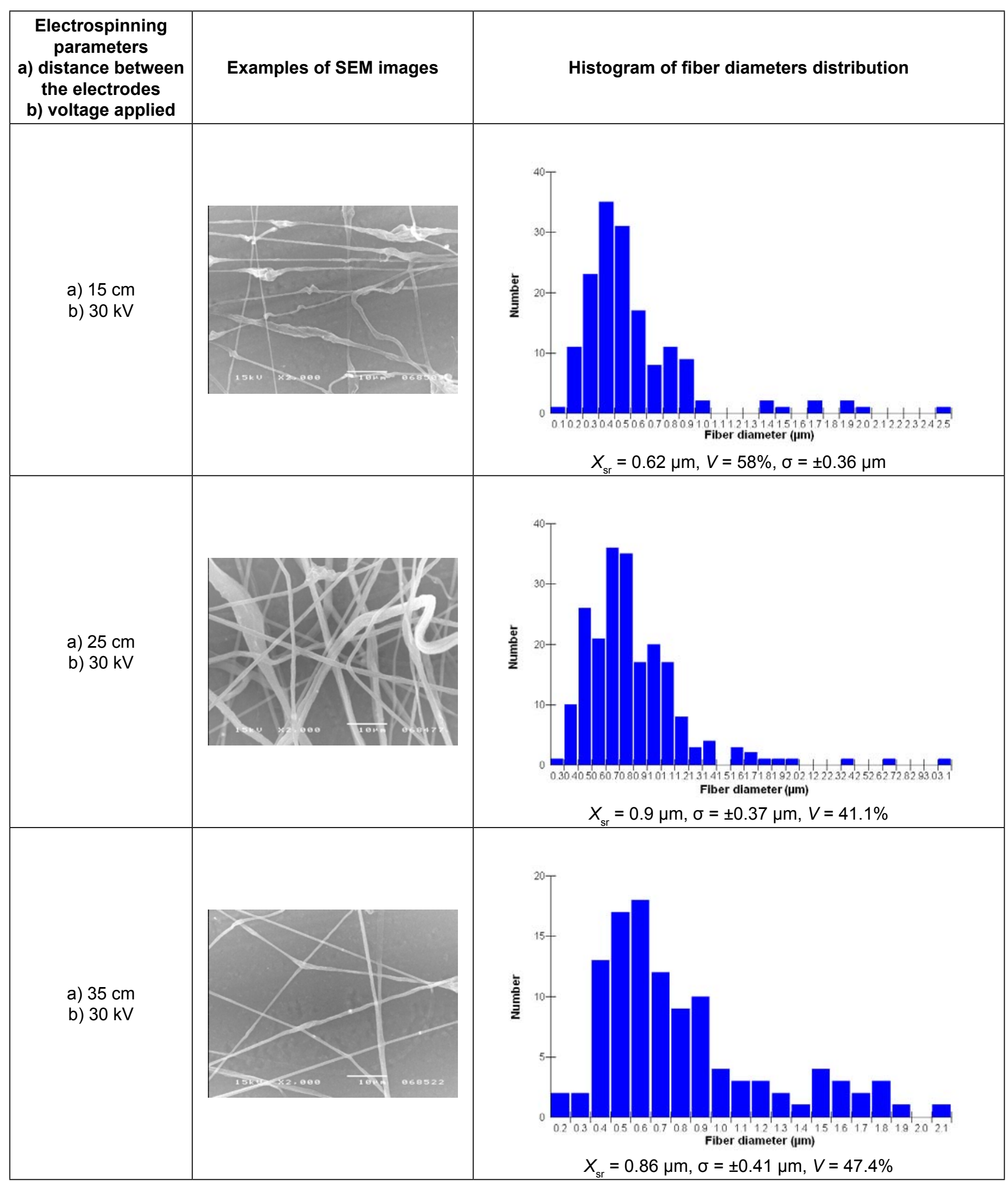

\section{Discussion and conclusions}

The presented results indicate that the use of spinning solutions of $4 \%$ and $6 \%$ wt concentrations prepared with dimethyl sulfoxide and dichloromethane combined in 50:50 proportion contributed to the formation of a substrate made up of fibers with considerably smaller transverse dimension than that of fibers electrospun from PLGA solution in pure dichloromethane. In the first case, fibers of transverse diameters within the 920-330 nm, depending on the formation conditions, were obtained, whereas in the second case the transverse dimensions ranged from 1700 to $3590 \mathrm{~nm}$. In the first case, the obtained fibers were also 
Table 7. Results of diameter measurements and images of fibers obtained by electrospinning from $4 \%$ PLGA with and without $1 \%$ HAp added in a mixture of solvents: dimethyl sulfoxide and dichloromethane in 50:50 proportion.

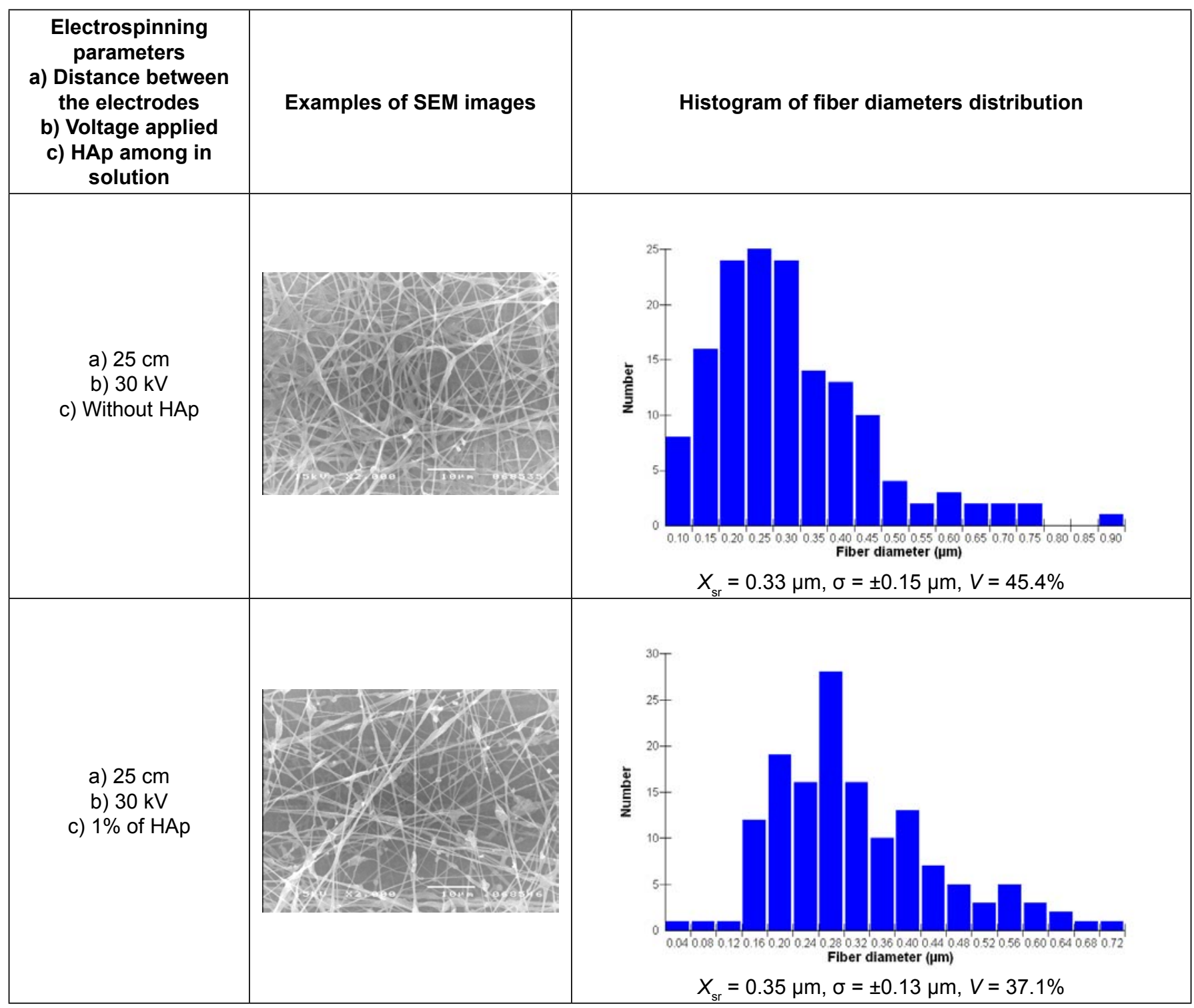

characterized by much less significant dispersion of transverse dimension values. Their variability coefficient fell within the $41.1-58 \%$ range for $6 \%$ PLGA solution, whereas in the second case the variability coefficient exceeded $100 \%$ in some instances. Therefore, it should be concluded on the basis of the study that using the mixture of dimethyl sulfoxide and dichloromethane in 50:50 proportion as a solvent for PLGA with $1 \%$ hydroxyapatite stabilizes the electrospinning process, which allows to obtain thin fibers of 620-900 nm transverse dimensions. More detailed analysis of fleeces obtained by electrospinning from solutions with DMSO and DCM mixture indicates that fibers formed from 6\% PLGA solutions with 1\% HAp and without HAp addition are characterized by higher transverse dimension values than fibers formed from $4 \%$ solutions, which has been illustrated in Tables 5, 6 and 7. For fibers formed from 6\% PGLA solution in DMSO/DCM mixture under optimal conditions, the transverse dimension equaled $0.67 \mu \mathrm{m}$ with the variability coefficient level of $28.3 \%$, whereas fibers formed from $4 \%$ solution under identical conditions $0.33 \mu \mathrm{m}$ with $45.4 \%$ variability coefficient. For analogical fiber fabrication variants with $1 \%$ addition of hydroxyapatite (in proportion to the polymer mass), the average transverse dimensions were as follows: for fibers obtained from $6 \%$ PLGA solution in DMSO/DCM mixture with 1\% HAp, formed under optimal conditions, the average diameter (taking into consideration, the transverse dimension and its dispersion) reached $0.9 \mu \mathrm{m}$ with variability coefficient of $41.1 \%$, whereas for fibers formed under the same conditions from $4 \%$ solution, the transverse dimension was $0.35 \mu \mathrm{m}$ with variability coefficient of $37.1 \%$.

\section{Conclusions}

1. The use of spinning solutions of $6 \%$ wt concentration, prepared with dimethyl sulfoxide and dichloromethane used in 50:50 proportion, allowed to obtain a substrate made up of fibers with significantly smaller transverse dimension and smaller dispersion of its values than in the case of electrospinning from PLGA polymer solution in pure dichloromethane. 
2. The use of spinning solutions of $4 \%$ PLGA concentration in the mixture of solvents, dimethyl sulfoxide and dichloromethane in 50:50 proportion with the addition of hydroxyapatite, contributed to obtaining fibers with significantly smaller transverse dimension than that obtained in the case of electrospinning from solutions with identical composition, but $6 \%$ polymer concentration. Under the same spinning conditions, reduction of the fiber transverse dimensions reached $50.7 \%$ for pure polymer and approximately $61 \%$ for the polymer with hydroxyapatite added.

3. Considering the stability of the spinning process, as well as the transverse dimension and its homogeneity, it

\section{References}

[1] Bastioli C., Handbook of Biodegradable Polymers, Rapra Technology Limited, 2005, UK, ISBN: 1-85957-389-4

[2] Auras R.A., Lim L.-T., Selke S.E.M., Tsuji H., Poly(Lactic Acid): Synthesis, Structures, Properties, Processing, and Applications, John Wiley \& Sons, 2011, Canada, ISBN: 978-0-470-29366-9

[3] Ikada Y., Tsuji H., Biodegradable polyesters for medical and ecological applications, Macromolecular Rapid Communications, Vol. 21, No. 3, pp. 117-132, 2000

[4] Auras R., Harte B., Selke S., An overview of polylactides as packaging materials. Macromolecular Bioscience, Vol. 4, pp. 835-864, 2004

[5] Guptaa B., Revagadea N., Hilborn J., Poly(lactic acid) fiber: An overview, Progress in Polymer Science, Vol. 32, pp. 455-482, 2007

[6] Weiler A., Hoffmann R.F.G., Stähelin A.C., Helling H.J., Südkamp N.P., Biodegradable implants in sports medicine: The biological base. Arthroscopy, The Journal of Arthroscopic and Related Surgery, Vol. 16, No. 3, pp. 305-321, 2000

[7] Eglin D., Alini M., Degradable polymeric materials for osteosynthesis: Tutorial, European Cells and Materials, Vol. 16, pp. 80-91, 2008

[8] Rudnik, E., Briassoulis, D., Degradation behaviour of poly (lactic acid) films and fibres in soil under Mediterranean field conditions and laboratory simulations testing, Industrial Crops \& Products, Vol. 33, Issue 3, pp. 648-658, 2011, DOI: 10.1016/j.indcrop.2010.12.031

[9] Gruber P., O'Brien M., Polylactides "NatureWorks TM PLA", Biopolymers Online, Wiley Online Library, pp. 235-239, 2005, DOI: 10.1002/3527600035.bpol4008

[10] Duda A., Penczek S., Polilaktyd [poli(kwas mlekowy)]: Synteza, właściwości i zastosowania, Polimery, Vol. 48, Issue 1, 2003

[11] Hyon S.H., Jamshidi K., Ikada Y., Synthesis of polylactides with different molecular weights, Biomaterials, Vol. 18, 1997

[12] Sodergad A., Stolt M., Properties of lactic acid based polymers and their correlation with composition, Progress in Polymer Science, Vol. 27, No. 6, Issue 41, pp. 11231163, 2002

[13] Garlotta D., A literature review of poly(lactic acid), Journal of Polymers and the Environment, Vol. 9, No. 2, 2001 should be assumed that the optimal spinning conditions were obtained with $30 \mathrm{kV}$ voltage applied to the upper electrode, $25 \mathrm{~cm}$ distance between the electrodes, $200 \mathrm{rpm}$ drum collector rotation speed and $0.9 \mathrm{~mm}$ capillary diameter.

\section{Acknowledgments}

The research was supported within the framework of a development project No. NR08-0032-10/2010 financed by the National Research and Development Center, as well as within the framework of the BIOGRATEX project "Biodegradable fibrous products" UDA-POIG.01.03.01-00-007/08-00.

[14] Sawpan M.A., Mechanical Performance of Industrial Hemp Fibre Reinforced Polylactide and Unsaturated Polyester Composites, Doctoral Dissertation, The University of Waikato, Hamilton, Nowa Zelandia, 2009

[15] Breteler M.R., Stereoselective Polymerization of Lactones. Properties of Stereocomplexed PLA Building Blocks, Doctoral Dissertation, University of Twente, Holandia, 2010, ISBN: 978-90-365-3045-3

[16] DobrzyńskiP., Bero M., KasperczykJ., Sposób wytwarzania bioresorbowalnych polimerów, Opis Patentowy PL 191 846 B1, 2000

[17] Smoła A., Dobrzyński P. et al., Nowe semikrystaliczne bioresorbowalne materiały z pamięcią kształtu, Engineering of Biomaterials, Vol. XII, No. 89-91, 2009

[18] Dobrzyński P., Synthesis of biodegradable copolymers with low-toxicity zirconium compounds. V. Multiblock and random copolymers of L-lactide with trimethylene carbonate obtained in copolymerizations initiated with zirconium(IV) acetylacetonate, Journal of Polymer Science: Part A: Polymer Chemistry, Vol. 44, pp. 31843201, 2006

[19] Bero M., Dobrzyński P., Kasperczyk J., Application of zirconium (IV) acetylacetonate to the copolymerization of glycolide with $\varepsilon$-caprolactone and lactide, Polymer Bulletin, 42, pp. 131-139, 1999

[20] Dobrzyński P., Initiation process of L-lactide polymerization carried out with zirconium(IV) acetylacetonate, Journal of Polymer Science: Part A: Polymer Chemistry, Vol. 42, pp. 1886-1900, 2004

[21] Dobrzyński P., Synthesis of biodegradable copolymers with low-toxicity zirconium compounds. III. Synthesis and chain-microstructure analysis of terpolymer obtained from L-lactide, glycolide, and $\varepsilon$-caprolactone initiated by zirconium(IV) acetylacetonate, Journal of Polymer Science: Part A: Polymer Chemistry, Vol. 40, pp. 31293143, 2002

[22] Czajkowska B., Dobrzynski P., Bero M., Interaction of cells with L-lactide/glycolide copolymers synthesized with the use of tin or zirconium compounds, Journal of Biomedical Materials Research Part A, Vol. 74A, Issue 4, pp. 591597, 2005

[23] Kasperczyk J., Hu Y., Jaworska J., Dobrzynski P., Wei J., Li S., Comparative study of the hydrolytic degradation of glycolide/L-lactide/E-caprolactone terpolymers initiated 
by zirconium(IV) acetylacetonate or stannous octoate, Journal of Applied Polymer Science, Vol. 107, pp. 32583266, 2008

[24] Burkersrodaa von F., Schedlb L., Göpferich A. Why degradable polymers undergo surface erosion or bulk erosion. Biomaterials, Vol. 23, pp. 4221-4231, 2002

[25] Woodruff M.A., Werner-Hutmacher D. The return of a forgotten polymer-Polycaprolactone in the 21st century, Progress in Polymer Science, Vol. 35, Issue 10, pp. 12171256, 2010

[26] Cicero J.A., Dorgan J.R., Physical properties and fiber morphology of poly(lactic acid) obtained from continuous two-step melt spinning, Journal of Polymers and the Environment, Vol. 9, pp. 1-10, 2001

[27] Yuan X., Mak Arthur F.T., Kwok K.W., Yung Brain K. O., Yao $K$., Characterization of poly(L-lactic acid) fibers produced by melt spinning, Journal of Applied Polymer Science, Vol. 81, pp. 251-260, 2001

[28] Nelson K.D., Romero A., Waggoner P., Crow B., Borneman A., Smith G.M., Technique paper for wet-spinning poly $(L-$ lactic acid) and poly(DL-lactide-co-glycolide) monofilament fibers, Tissue Engineering, Vol. 9, No. 6, pp. 1323-1330, 2003

[29] Kulkarni R.K., Pani K.C., Neuman C., Leonard F., Polylactic acid for surgical implants, Archives of Surgery, Vol. 93, No. 5, pp. 839-843, 1966

[30] Ikada Y., Gen S., Polylactic Acid Fiber - Patent 5010145 , Daicel Chemical Industries, Ltd.,

[31] Rissanen M., Puolakka A., Ahola N., Tonry A., Rochev Y., Kellomäki M., Nousiainen P., Effect of protein-loading on properties of wet-spun poly(L,D-lactide) multifilament fibers, Journal of Applied Polymer Science, Vol. 116, pp. 2174-2180, 2010

[32] Gao H., Gu Y., Ping Q., The implantable 5-fluorouracilloaded poly(L-lactic acid) fibers prepared by wet-spinning from suspension, Journal of Controlled Release, Vol. 118, No. 3, 23, pp. 325-332, 2007

[33] Boguń M., Krucińska I., Król P., Szparaga G., Mikołajczyk T., Dobrzyński P., Kowalczuk M., Kasperczyk J., Pastusiak M., Smoła A., Sposób wytwarzania włókien o rozmiarach mikrometrycznych i podwyższonych właściwościach wytrzymałościowych z poli(kwasu mlekowego) oraz jego kopolimerów metodą z roztworu na mokro, Opis patentowy PL P-399819, 2012

[34] Kumar C.S.S.R., Nanotechnologies for the Life Sciences, Vol. 9, Tissue, Cell and Organ Engineering, WILEY-VCH Verlag GmbH \& Co. KGaA, Weinheim, 2006, ISBN: 3-527-31389-3

[35] Subbiah T., Bhat G.S., Tock R.W., Parameswaran S., Ramkumar S.S., Electrospinning of nanofibers, Journal of Applied Polymer Science, Vol. 96, pp. 557-569, 2005

[36] Garg K., Bowlin G.L., Electrospinning jets and nanofibrous structures, Biomicrofluidics, Vol. 5, No. 1, 2011

[37] Li J., He A., Han C.C., Fang D., Hsiao B.S., Chu B., Electrospinning of hyaluronic acid (HA) and HA/gelatin blends, Macromolecular Rapid Communications, Vol. 27, pp. 114-120, 2006

[38] Huang Z.-M., Zhang Y.-Z., Kotaki M., Ramakrishna S., A review on polymer nanofibers by electrospinning and their applications in nanocomposites, Composites Science and Technology, Vol. 63, pp. 2223-2253, 2003
[39] Andrady A.L., Science and Technology of Polymer Nanofibers, John Wiley \& Sons, Inc., 2008

[40] Ramakrishna S., An Introduction to Electrospinning and Nanofibers, World Scientific Publishing Company, 2005

[41] Lu P., Ding B., Applications of electrospun fibers, Recent Patents on Nanotechnology, Vol. 2, pp. 169-182, 2008

[42] Burger C., Hsiao B.S., Chu B., Nanofibrous materials and their applications, Annual Review of Materials Research, Vol. 36, pp. 333-368, 2006

[43] Ji W., Sun Y., Yang F., van den Beucken J.J.J.P., Fan M., Chen Z., Jansen J.A., Bioactive electrospun scaffolds delivering growth factors and genes for tissue engineering applications, Pharmaceutical Research, Vol. 28, pp. 1259-1272, 2011, DOI 10.1007/s11095-010-0320-6

[44] Liu W., Thomopoulos S., Xia Y., Electrospun nanofibers for regenerative medicine, Advanced Healthcare Materlals, Vol. 1, pp. 10-25, 2012

[45] TeoW.-E., Inai R., Ramakrishna S., Technological advances in electrospinning of nanofibers, Science and TechnolOgy of Advanced Materials 12, 2011doi:10.1088/14686996/12/1/013002

[46] Ponclet D., de Vois P., Suter N., Jayasinghe S.N., Bioelectrospraying and cell electrospinning: Progress and opportunities for basic biology and clinical sciences, Advanced Healthcare Materials, Vol. 1, Issue 1, pp. 2634, 2012

[47] lonescu L.C., Lee G.C., Sennett B.J., Burdick J.A., Mauck R.L., An anisotropic nanofiber/microsphere composite with controlled release of biomolecules for fibrous tissue engineering, Biomaterials, Vol. 31, Issue 14, pp. 41134120, 2010

[48] Lim L.-T., Auras R., Rubino M., Processing technologies for poly(lactic acid), Progress in Polymer Science, Vol. 33, Issue 8, pp. 820-852, 2008

[49] Ji W., Sun Y., Yang F., van den Beucken J.J.J.P., Fan M., Chen Z., Jansen J.A., Bioactive electrospun scaffolds delivering growth factors and genes for tissue engineering applications, Pharmaceutical Research, Vol. 28, pp. 1259-1272, 2011, DOI 10.1007/s11095-010-0320-6

[50] Liu W., Thomopoulos S., Xia Y., Electrospun nanofibers for regenerative medicine, Advanced Healthcare Materials, Vol. 1, No. 1, pp. 10-25, 2012

[51] Chew S.Y., Wen Y., Dzenis Y., Leong K.W., The role of electrospinning in the emerging field of nanomedicine, Current Pharmaceutical Design, Vol. 12, Issue 36, pp. 4751-4770, 2006

[52] Buschle-Diller G., Cooper J., Xie Z., Wu Y., Waldrup J., Ren $X$. , Release of antibiotics from electrospun bicomponent fibers, Cellulose, Vol. 14, pp. 553-562, 2007, DOI 10.1007/s10570-007-9183-3

[53] Bhattarai S.R., Bhattarai N., Viswanathamurthi P., Yi H.K., Hwang P.H., Kim H.Y., Hydrophilic nanofibrous structure of polylactide; fabrication and cell affinity, Journal of Biomedical Materials Research Part A, Vol. 78, Issue, 2 , pp. 247-257, 2006

[54] Lu P., Ding B., Applications of Electrospun fibers, Recent Patents on Nanotechnology, Vol. 2, pp. 169-182, 2008

[55] Pillai C.K.S., Sharma C.P., Electrospinning of chitin and chitosan nanofibres, Trends in Biomaterials and Artificial Organs, Vol. 22, Issue 3, pp. 179-201, 2009 